\title{
LA RELACIÓN ENTRE LAS TEORÍAS DE LAS REPRESENTACIONES SOCIALES Y LA IMPORTANCIA DE SU ESTUDIO EN LOS DOCENTES UNIVERSITARIOS
}

\section{THE RELATIONSHIP BETWEEN THE THEORY OF SOCIAL REPRESENTATIONS AND THE IMPORTANCE OF THEIR STUDY IN UNIVERSITY TEACHERS}

\author{
Martha Lucía Arias-Holguín' \\ Pedro Ignacio Moya-Espinosa ${ }^{2}$
}

Recibido: febrero 26 de 2015

Aceptado: mayo 28 de 2015

\begin{abstract}
Resumen
La teoría de las Representaciones Sociales ha sido objeto de estudio para analizar diversos y variados problemas; sin embargo, son pocas las investigaciones que abordan desde esta teoría el campo de estudio acerca del docente universitario. El objetivo de la presente reflexión es el de establecer la relación entre el profesor universitario y la importancia del abordaje de sus Representaciones Sociales, constituyendo un aporte para fundamentar su análisis e investigación. Se conceptualiza desde diversos autores acerca del significado del término de Representaciones Sociales y se plantea la importancia de su estudio para analizar el quehacer del docente universitario, sujeto agente del cambio en pro de la calidad educativa de la universidad. Se concluye que la educación superior debe posibilitar el conocimiento de las representaciones sociales que circulan en el contexto educativo, analizando su incidencia en el comportamiento individual y grupal, permitiendo comprender el trabajo de los actores educativos, su impacto e intervención en los procesos encaminados hacia una mejor educación.
\end{abstract}

Palabras Clave: Representaciones Sociales, Imagen, Rol docente, Práctica académica, Docente Universitario.

\begin{abstract}
The theory of social representations has been studied to analyze diverse and varied problems; however, little research based on this theory from the field of study of the university teacher has been addressed. The aim of this reflection is to establish the relationship between the professor and the importance of mentioning their social representations, constituting a contribution to support its analysis and research. It is conceptualized from different authors about the meaning of Social Representations and the importance of their study to analyze the work of university teachers, subject agent of change for the educational quality of the university. We conclude that higher education should enable the knowledge of Social Representations, circulating in the educational context by analyzing their impact on individual and group behavior, allowing the understanding of the work of educational actors, their impact and intervention in processes leading to a better education.
\end{abstract}

Keywords: Social Representations, Image, teaching role, academic Practice, University Teachers.

\footnotetext{
1 Licenciada en Ciencias de la Educación, Fundación Universitaria Remington FUR-CAT Duitama, Colombia. E-mail:maluah.ariasholguin@gmail.com

2 Administrador de Empresas, Magíster en Ciencias de Desarrollo Empresarial, Universidad Pedagógica y Tecnológica de Colombia, Colombia. E-mail: pedro.moya@uptc.edu.co
} 


\section{Introducción}

La educación a través de la historia se ha visto influenciada por la realidad del mundo circundante, y como proceso de desarrollo personal y social se enmarca en un contexto que la circunscribe ofreciéndole un panorama de imágenes, modelos y significados ligados al papel del docente, quien con el ejercicio de su saber, de su ser y de su hacer, ofrece una representación.

Los cambios sociales, culturales y económicos inciden de manera directa en los planteamientos educativos, lo que exige cambios estructurales del sistema educativo en las prácticas y en el rol del docente, en las representaciones sociales, en su entorno de acción, es decir, en el aula de clase. La educación actual requiere de adaptaciones culturales, sociales, laborales, profesionales y personales, acordes con los cambios del mundo actual. Es por estas razones que estudiar, analizar y reflexionar acerca de las representaciones sociales de los docentes universitarios se convierte en un tema de discusión y prospección. Las siguientes son las preguntas que orientan la presente reflexión: Qué fundamentos teóricos y conceptuales soportan las representaciones sociales de los docentes universitarios?; Cuál es el papel del docente universitario y cuál es su importancia?; Cuál es la incidencia de las representaciones sociales en la práctica académica del docente universitario?.

El objetivo de la presente reflexión es el de establecer la relación entre el profesor universitario y la importancia del abordaje de sus Representaciones Sociales, constituyendo un aporte para fundamentar su análisis e investigación. Para ello se hace una revisión teórica y conceptual acerca del significado del término de las representaciones sociales, como base para investigaciones más profundas.

La reflexión se soporta en una investigación de tipo exploratorio, con un enfoque cualitativo y métodos deductivo e inductivo. La justificación se argumenta en la importancia de tratar estas temáticas como fundamento de aproximación a la visión del mundo que los individuos o grupos tienen. Posibilita entender la dinámica de las interacciones sociales y aclarar sus prácticas, ya que la representación, el discurso y la práctica se generan mutuamente. Permite asumir una posición frente al rol de docente, su práctica académica y la imagen que se constituye en decisiva en un proceso de formación.

\section{Referentes conceptuales}

\subsection{Metodología}

Este documento se soporta en una investigación exploratoria que pretende dar una visión general, de tipo aproximativo, respecto a las representaciones sociales y las prácticas académicas del docente universitario. Su enfoque es cualitativo y los métodos utilizados son el deductivo, que parte de los datos generales aceptados como valederos, para deducir por medio del razonamiento lógico, para luego aplicarlo a casos individuales, y el inductivo, que va de lo particular a lo general. El método empleado se basa en principios teóricos que permiten identificar las representaciones sociales que circulan en el medio académico de los docentes universitarios.

El estudio de las representaciones sociales plantea un amplio espectro de posibilidades metodológicas, lo que implica definir la más acorde con la recolección y procesamiento de la información, que conduzca al diseño de un análisis lógico, de un estudio que no puede ser una secuencia lineal direccional, sino un proceso que avanza a través de contradicciones.

\subsection{Revisión Conceptual}

La representación social es una modalidad particular del conocimiento, cuya función es la elaboración de los comportamientos y la comunicación entre los individuos. Es una estructura organizada de conocimientos y una de las actividades menta- 
les mediante las cuales los individuos hacen apreciable la realidad física y social, y se integran en un grupo o en una relación cotidiana de intercambios; son sistemas de valores, nociones y prácticas que provee a los individuos de los medios para orientarse en el contexto social; es una organización de imágenes y de lenguaje, Moscovici (1961). Jodelet (1986), incorpora otros elementos refiriéndose a que las representaciones sociales son imágenes cargadas de significados; son sistemas de referencia que permiten interpretar lo que sucede e incluso dan un sentido a lo inesperado; categorías que sirven para clasificar las circunstancias, los fenómenos y a los individuos con quienes se tiene algún tipo de interrelación e interacción (Jodelet, D., citado por Pereira, 1999, p.9).

Algunos estudios plantean que las representaciones sociales originan los significados que la gente necesita para comprender, actuar y orientarse en su medio social. En este sentido, las representaciones actúan de forma semejante a las teorías científicas ya que son teorías de sentido común que permiten describir, clasificar y explicar los fenómenos de las realidades cotidianas. (Ibañez, 1988, p.55). Otras investigaciones han planteado que las representaciones sociales son ante todo "productos socioculturales", pues proceden de la sociedad e informan sobre características propias de grupos que las asumen.

Para Ibáñez (1988, p. 32) en efecto, la definición de representación social ha sido uno de los aspectos más controvertidos dentro de este campo de estudios. Primero, habría que empezar preguntándose: ¿Qué se entiende por representación, comúnmente? En el teatro, para citar un ejemplo particular, representar implica una sustitución aparente, poner algo en el lugar de otra cosa. Esta metáfora no es casual: una representación puede referirse lo mismo a objetos ideales que a reales, tanto ausentes como presentes.

Para Jodelet (1986, p. 476), citando a Moscovici, dice que si bien es fácil captar la realidad de las representaciones sociales, no es nada fácil captar el concepto y que en el acto de representación siempre se relaciona un sujeto (grupal e individual) con un objeto determinado. Así representar es, en el sentido estricto de la palabra, volver a presentar, o sea, re-producir, que no reproducir, un objeto cualquiera mediante un mecanismo alegórico. Esta re-producción siempre es subjetiva en última instancia. Jodelet (1991) "En la representación se tiene el contenido mental concreto de un acto de pensamiento que restituye simbólicamente algo ausente que aproxima algo lejano; Particularidad importante que garantiza a la representación su aptitud para fusionar precepto y concepto y su carácter de imagen." En todo caso, la representación siempre es portadora de un significado asociado que le es inherente. Al ser formulada por sujetos sociales, no se trata de una simple reproducción sino de una complicada construcción en la cual tiene un peso importante, además del propio objeto, el carácter activo y creador de cada individuo, el grupo al que pertenece y las constricciones y habilitaciones que lo rodean.

La noción de "representación social" ha dado lugar a la teoría de las Representaciones Sociales, convirtiéndose en un nuevo marco de trabajo para todas las ciencias sociales ya que dicho término ha rebasado la psicología social europea, disciplina que lo acuñó. Las representaciones sociales surgen con el replanteamiento de Moscovici del concepto de Representaciones Colectivas de Durkheim. El hecho de que cualquier corriente de pensamiento está atravesada por la relación entre lo individual y lo social plantean el problema de qué conjunto de determinantes del conocimiento y la conducta tienen prioridad: si los que provienen del interior del individuo o los que provienen de la red de relaciones humanas.

La representación, desde la aparición del conductismo, siempre ha sido la característica distintiva de la psicología cognitiva. De esta manera la representación ha dado credibilidad científica a la mente como objeto de estudio, Perner (1991). Desde esta óptica psicosocial es un mecanismo de cognición y un mecanismo de socialización y 
de comunicación a lo largo del desarrollo humano. Para Moscovici (1981) las representaciones sociales son "La elaboración de un objeto social por la comunidad con el propósito de conducirse y comunicarse." La cognición social y las representaciones sociales pueden dar lugar a teorías que funcionen como paradigmas dando lugar a lo que Shapere (1979) y Caparrós (1984) Ilaman investigaciones "tipo dominio". Un dominio puede ser caracterizado como un tema unificado o como un conjunto de fenómenos y de observación que tienen relación entre sí, hasta el punto de presentar cierta unidad. Como ejemplo podemos citar ansiedad, agresividad, adquisición del lenguaje, motivación del rendimiento y aprendizaje social, García (2007). Para que un conjunto de fenómenos e informaciones se constituyan en dominio es preciso que se perciban por los investigadores con cierta relación y unidad, que lo identifique como tal y, además, ha de presentar cierta problematicidad que exija investigación.

\subsection{Revisión Teórica}

La teoría de las Representaciones Sociales aborda una forma de conocimiento social específica de las sociedades modernas. Concibe las representaciones como un producto colectivo con capacidad de construir un determinado modo de vida al tiempo que orienta el pensamiento y la acción de los individuos. Explica el surgimiento de las representaciones a través de procesos de comunicación, diálogo y negociación de significados y sostiene que las representaciones poseen un cierto grado de estructuración, Jodelet y Moscovici (1989). En este sentido, los comportamientos cotidianos son inducidos por las representaciones personales que cada uno tiene de la realidad. Estas representaciones se constituyen como guías y generadoras de comportamientos. Moscovici (1988), concibe las Representaciones como un sistema cognitivo con una lógica y un lenguaje propio, que constituyen un sistema de creencias, valores e ideas. Son una manera de comunicar, comprender, predeciry analizar comportamientos.
En el campo educativo, las representaciones sociales han tomado gran importancia como una forma de explicar el comportamiento del docente en su labor educativa, Elgueta (1998). Se puede decir que las creencias y concepciones del docente acerca de los alumnos y de la interacción entre estos, incidirán en cómo el docente explica y desarrolla las acciones tanto pedagógicas como didácticas en el aula. La diferencia entre las representaciones de los profesores y las que tiene el alumno frente al aprendizaje, dan lugar a un gran número de conflictos en la interacción educativa. Casado y Martínez (1998) es importante resaltar las funciones que le atribuyen a las representaciones sociales en el intercambio y transmisión de saberes, lo que denomina Moscovici como "saber práctico de sentido común; en la orientación y prescripción del comportamiento; en su justificación y por último en la elaboración de una identidad personal y grupal compatible con las normas y valores sociales e históricamente determinados, lo que posibilita que las personas se reconozcan como parte de un grupo determinado y actúen de acuerdo con las expectativas del mismo" como se puede observar en la figura 1.

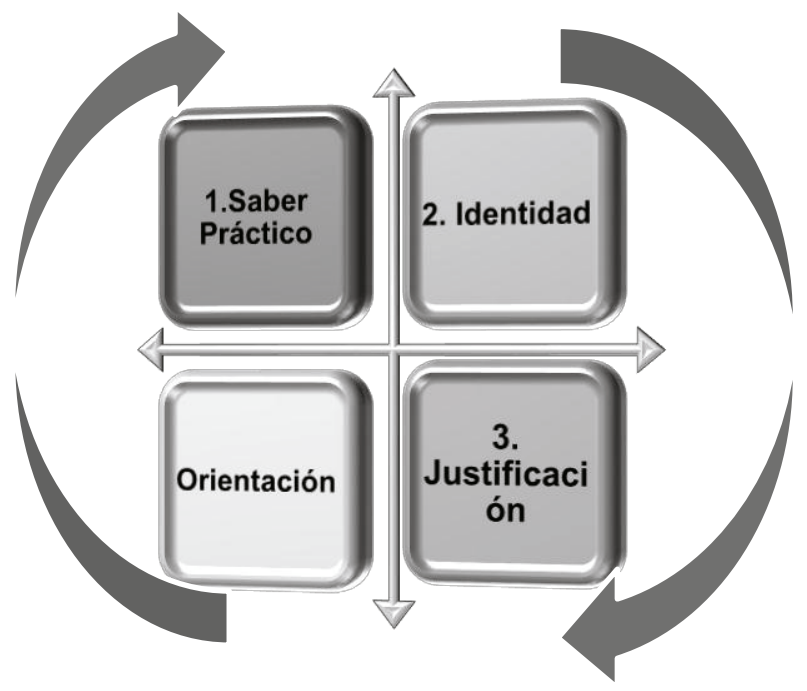

Figura 1. Funciones básicas de las Representaciones Sociales, adaptado de (Moscovici, 1988). 
Desde la perspectiva del modelo teórico es importante destacar que para reconocer la teoría de las Representaciones Sociales desde su génesis, el modelo teórico se centra en que estas buscan entender los modos de conocimiento y los procesos simbólicos en relación con la conducta, las acciones y el comportamiento del docente. En este sentido, un aspecto importante es el de la identificación del contexto social del docente universitario para identificar su ideología, normas, valores, actitudes, imagen, conceptos y preceptos.

Conocer o establecer una representación social implica determinar qué se sabe (información), qué se cree, cómo se interpreta (campo de la representación), y qué se hace y cómo se actúa (actitud). Estas tres dimensiones halladas por Moscovici forman un conjunto que tan solo puede partir para satisfacer las exigencias propias del análisis conceptual. De acuerdo con Balduzzi (2011), la teoría de las Representaciones Sociales ha sido concebida en el interior de una disciplina, la psicología social, que tiene objetos teóricos, conceptos y procedimientos propios. En primer lugar, ha jugado un rol de proposición original en vistas a reinsertar la psicología social en el espacio social, gracias a una mirada específica, la mirada psicosociológica, articulando siempre en relación al mundo un sujeto y un alter (Moscovici, 1984). En segundo lugar, ofrece también herramientas conceptuales y metodológicas fecundas para el estudio de problemas sociales concretos. Sin embargo, no puede ser reabsorbida en las transferencias que se hacen en campos vecinos. El ajuste entre las problemáticas y perspectivas de estos dos dominios científicos es una tarea apenas iniciada.

En efecto, el campo de la educación ofrece un espacio privilegiado para el estudio de las relaciones dialécticas existentes entre los diferentes elementos de sistemas complejos. Estas representaciones son localizables en contextos institucionales y prácticas concretas a través del discurso de los diferentes actores, deben ser abordadas de una manera histórica que tome en cuenta la evolución de las políticas educativas, de las poblaciones ha- cia las cuales la educación se dirige en razón de la masificación y la democratización de la escuela, de las posiciones y de las identidades que resultan de este modo entre los participantes de la relación pedagógica. De hecho, el campo de la educación aparece como uno de los más fecundos para la aplicación de un enfoque en términos de representaciones sociales y sus diversas metodologías. La introducción del estudio de las representaciones sociales en las investigaciones francesas y europeas sobre la educación se remonta a la década de 1970. Los primeros trabajos han tratado sobre el rol de los conjuntos organizados de significaciones en el seno del sistema y del proceso educativo (Gilly, 1980).

\subsection{El docente universitario}

Para interpretar el papel del docente universitario es necesario analizar una serie de retos e implicaciones para los profesionales que incursionan en el entramado y complejo mundo del proceso de enseñanza- aprendizaje. El docente es un individuo que se forma, se prepara y adquiere una serie de competencias profesionales y laborales y se dedica a enseñar; es la persona que imparte conocimientos enmarcados en una determinada ciencia, arte u oficio. La palabra se deriva del término docens, que procede de docēre (enseñar). Se asemeja con los términos profesor o maestro. Aunque los términos no signifiquen lo mismo es necesario interpretar que el maestro cuenta con habilidades que son extraordinarias en alguna materia para instruir. En este orden de ideas, llámese profesor o maestro, lo que se convierte en tema común es que los dos deben poseer habilidades pedagógicas para ser un actor efectivo del proceso de aprendizaje.

Es importante destacar que el docente cuenta con habilidades para enseñar y la docencia se entiende como la actividad de enseñar a través de la interacción de tres elementos: El docente, el alumno y el objeto de conocimiento. Una concepción teórica, filosófica e idealista conjetura que el docente tiene como deber la transmisión de sus saberes 
al alumno mediante diversas mediaciones, elementos, técnicas, ayudas y herramientas. De este modo el docente asume el rol de fuente de conocimientos y el educando se convierte en un receptor ilimitado de todo ese saber. El papel que desempeña el docente en la vida de sus estudiantes se ve reflejado en el quehacer de estos, quienes en un momento determinado repiten o reproducen la transmisión de tales conocimientos, valores, principios e imágenes que reflejan las representaciones de los profesores frente a los estudiantes.

La labor del docente universitario, en cuanto al acompañamiento de los aprendizajes, está directamente relacionado con la calidad de la educación. Para este artículo se asume como escenario la universidad, ambiente donde el docente desarrolla su práctica académica; para esto se hace necesario revisar de manera resumida la presencia de esta a través de la historia, para identificarla en las diferentes épocas. Las universidades tienen su origen en el mundo antiguo, donde sobresalen las escuelas de filosofía ateniense, escuelas de Alejandría (relacionadas con bibliotecas), escuelas Brahmánicas (según la UNESCO, la universidad más antigua del mundo), la Educación Superior India, las escuelas Árabes, Chinas y Romanas, esta última asociada con temas jurídicos y el Senado de Roma. Es de significar que estas escuelas atendían dos propósitos fundamentales: la docencia y la investigación de alto nivel. Las universidades del Renacimiento, Napoleónica, Republicana, alemana, japonesa, soviética, americana y latinoamericana, se preocuparon por tres propósitos, así: Docencia, investigación y servicios a la comunidad; por último, en este proceso evolutivo, se destacan en la actualidad las 'mega universidades' con educación a distancia, virtual, global y de clase mundial que atienden aspectos como la pertinencia global, con estudiantes y docentes globales y mantienen el propósito de la docencia, la investigación y la extensión, agregando temas como la internacionalización y la multiculturalidad. De esta manera se puede decir que el docente, como parte fundamental de la tríada universidad-estudiante-docente, ha tenido un papel protagónico, enmarcado en las representaciones sociales en cada momento histórico (UNESCO, 2014).

\subsection{Las representaciones sociales y el papel del docente universitario}

En un mundo caracterizado por el cambio, la educación en todos sus niveles y particularmente en el superior, se ve frente a un paradigma que es complejo y del cual no está exento el docente universitario, su rol y, por supuesto, las representaciones sociales como ejercicio de la actividad de formación. Es así como en las últimas décadas ese paradigma teórico, visto desde diversos enfoques, ha ido pasando de la enseñanza al aprendizaje, como eje de la dinámica educativa y donde las personas construyen su propio conocimiento en sus experiencias, recorridos e intereses en el marco de diversidad de saberes, modalidades, pedagogías y entornos. Sin embargo la práctica educativa de la enseñanza tradicional, catedrática, memorística, presencial, masiva, disciplinaria, lineal y jerarquizada está siendo remplazada por la enseñanza que se apoya en la expansión de los saberes, la educación permanente, las tecnologías de la información y la comunicación (TIC); el cambio del trabajo profesional, la interdisciplinariedad y la diversidad, la flexibilidad y la movilidad de los currículos.

La educación enfrenta un paradigma complejo, producto de la dinámica de la nueva complejidad educativa, globalizada, internacionalizada y externalizada, en el cual el docente asume el protagonismo a partir del papel que desempeña en el aula de clase, con modalidades selectivas de acceso con complejos sistemas universitarios abiertos en circuitos distintos de calidad, y que tienden a promover una sobreoferta de profesionales diversos, nuevas regulaciones del gobierno, las demandas de equidad, calidad y pertinencia; la evaluación y acreditación, la diferenciación institucional, certificación y recertificación de competencias. La expansión del conocimiento, la segmentación de los saberes y la diferenciación de las titulaciones y de las instituciones, las regulaciones internacionales, 
la educación superior global en un marco de un proceso de convergencia, es justo donde las representaciones sociales se convierten en un insumo de gran interés para estudiar, analizar y reflexionar.

\subsection{Incidencias de las representaciones socia- les en la práctica académica del docente uni- versitario}

Las representaciones sociales reflejan un conjunto de atributos identificables que se constituyen en representativos del quehacer docente, donde se destacan las competencias profesionales, personales y -por qué no decirlo-, histriónicas, que dan cuenta del lenguaje, el conocimiento, la gestualidad y el comportamiento del docente en el aula de clase. Abordar el tema de las representaciones sociales permite ahondar en factores que influyen de manera significativa en la formación de los profesionales, para analizar cómo se incide de manera directa e indirecta en la calidad de lo enseñado y lo aprendido, así como establecer un ejercicio de autorregulación que permite el mejoramiento continuo. En este orden de ideas es necesario destacar los puntos de vista de algunos autores donde se establece cómo las representaciones sociales influyen, explican, legitiman, construyen y afectan los procesos de aprendizajes, así:

Según Cardoso (2011), hasta la década de los años 90 , las llamadas, hasta ese momento investigaciones sobre concepciones docentes, demostraban que tales concepciones influyen de manera significativa en la práctica docente dentro y fuera del aula y por eso hay que tenerlos en cuenta durante la elaboración e implementación de propuestas de mejoramiento del proceso de enseñanza aprendizaje.

Casado y Calonge (2000), afirman que "Aunque el estudio de las representaciones sociales en el contexto educativo es muy reciente, se constituyen en una vía para explicar los factores sociales que inciden en los procesos educativos y en sus resultados.
Para Gilly (1986), las representaciones sociales explican y legitiman prácticas educativas, así como la calidad y tipo de interacciones que se dan en el ámbito educativo.

Alves (2008), señala: los estudios muestran que cada grupo, cada segmento sociocultural, tienen su conjunto de representaciones sobre diferentes aspectos de su vida, las cuales, nosotros, educadores e investigadores, insistimos en no oír. Como grupo socio-profesional, construimos nuestras propias representaciones y en función de ellas construimos nuestras prácticas y las imponemos a los alumnos, suponiendo que sabemos lo que es bueno para ellos. Si el conocimiento de las representaciones sociales, las de nuestros alumnos y la de sus familias, así como las nuestras, nos pueden ayudar a alcanzar una mayor descentración en lo que se refiere a los problemas educacionales, ya habrá demostrado su utilidad.

Castorina (2012), se centra en los procesos de cambio educativo y considera que para que haya un cambio se requiere del abordaje de las representaciones sociales de los sujetos, considerando su influencia en el comportamiento de las personas, en las actitudes hacia los demás y por consiguiente en las dinámicas de las instituciones, entre ellas las educativas y los procesos que las caracterizan relacionadas con la formación, la enseñanza y el aprendizaje.

Ayala (2009), indica que las concepciones, saberes e ideas de los diferentes actores educativos afectan de manera directa su vida académica en relación con la institución, la carrera que eligen, los docentes y los recursos de los que dispongan, siendo los estudiantes los que definen qué se considera como calidad educativa.

\section{Discusión}

Este espacio lo integran tres aspectos, así: estudio de las representaciones, vigencia y tendencias. 
Estudio de las representaciones sociales. Partiendo de los postulados teóricos y conceptuales tratados anteriormente cabe destacar cómo estudiar, analizar y comprender las representaciones sociales. Para ello es necesario subrayar que, para su estudio se han utilizado diversos métodos e instrumentos, sin que hasta ahora se pueda establecer uno como el mejor o el más indicado, ya que dada la heterogeneidad y la diversidad de variables que se pueden estudiar, hay quienes privilegian unos más que otros, lo que permite ver un gran panorama de posibilidades en cuanto a métodos, técnicas e instrumentos; donde las entrevistas, los grupos foco, talleres de percepción y encuestas, entre otros son instrumentos de gran valor.

Por la importancia, amplitud y complejidad del fenómeno representacional es necesaria la combinación de enfoques y perspectivas teóricas que se puedan articular con el propósito de un mayor acercamiento al mismo. Una de las vías para acceder a su conocimiento se centra en el campo de la comunicación y la interpretación, ya que mediante los "discursos" de los sujetos se pueden generar interacciones cuya trascendencia radica en que es una práctica que construye sistemáticamente el objeto del cual se habla.

Según Mireles (2011), los estudios empíricos sobre las representaciones sociales adoptan una metodología de corte cualitativo que pretende acercarse al contenido más que a la estructura cognitiva de las representaciones sociales. En este sentido es usual encontrar trabajos que utilizan la historia de vida, el estudio de caso, la entrevista en profundidad y la observación participante (Jodelet, 2000; Mireles, 2008).

Para el enfoque procesual se privilegian métodos de recolección y análisis cualitativos, aun cuando se haga uso de números y la triangulación para garantizar la confiabilidad de la interpretación; en el enfoque estructural se utilizan técnicas correlacionales y métodos multivariados o ecuaciones estructurales. Se sugiere que el investigador ajuste las técnicas de recolección de datos al objeto de estudio para recuperar la información primaria y someterla a análisis e interpretación.

Si el objeto es dar cuenta de la génesis histórica de una representación, hay que trabajar desde la perspectiva original de Serge Moscovici o de Denise Jodelet. Si el interés es comparar las representaciones sociales de dos grupos o de un mismo grupo en diferentes ocasiones, se sugiere la perspectiva estructural del grupo del Midi (universidades de Aix-en Provence y Monpellier, Francia) técnica de análisis cualitativo para elaborar un índice que permitió determinar los componentes nucleares y periféricos de las representaciones, $\mathrm{Pe}$ reira de Sá, (1998). Si se quiere saber sobre cómo inserciones sociales de los sujetos condicionan sus representaciones, se debe recurrir al recurso teórico de Doise (1993), sin embargo, si se pretende estudiar el contenido cognitivo de las representaciones sociales, concibiéndolo como un conjunto organizado o estructurado y no como simple conexión de ideas y valores, la perspectiva debe ser la de Abric (1994), más conocida como la de "Núcleo Central".

La entrevista es un método que permite indagar de manera estructurada, preparada con anticipación y con preguntas ya definidas, o no estructurada, se va profundizando de acuerdo con el desarrollo de la entrevista; en los dos casos es de manera fundamental ahondar para indagar acerca de las variables que permiten el estudio de las Representaciones Sociales. Mediante la indagación se puede codificar, categorizar y agrupar las respuestas de los docentes lo que permite integrar relatos de vida que son un conjunto de narraciones breves en las que se expresan acerca de su experiencia en el aula de clase, reproducir los acontecimientos más significativos, inducir a un diálogo de saberes abierto; lo cual implica gran conocimiento, habilidad y experiencia de quien entrevista para buscar profundizar y lograr encontrar aspectos de gran interés.

A través de técnicas como la entrevista en profundidad y las asociaciones de palabras se puede te- 
ner acceso a los discursos que por su naturaleza favorece la espontaneidad y la naturalización de la situación de intercambio. Es necesario considerar un importante precepto que plantea esta teoría: Toda Representación es siempre de algo (el objeto) y de alguien: el sujeto, la población o grupo social; por lo tanto es importante señalar algunos aspectos metodológicos para este tipo de estudios, así:

-Enunciar de manera precisa la entrevista.

-Determinar los sujetos en cuyas manifestaciones discursivas y comportamientos se estudiará las representaciones sociales.

-Determinar las dimensiones del contexto sociocultural donde se desenvuelven los sujetos.

Vigencia. La vigencia de las representaciones sociales es tan antigua como el hombre, solamente que a partir de teóricos antes enunciados como Moscovici, y Jodelet entre otros pareciera que el tema solamente se estudia desde hace aproximadamente Sesenta años, tal vez por ser a partir de este momento histórico que aparecen escritos y autores que dan cuenta de tal hecho donde estas son asociadas con la Psicología Social, el interaccionismo simbólico, el núcleo central, el principio de toma de posición, el producto dialógico entre otros, como una forma de construir la realidad actual en la sociedad. Quizá resulte una postura crítica esta afirmación, pero es necesario entender que para tratar el tema de las representaciones sociales, y para el caso concreto del docente universitario, se requieren el objeto, el sujeto y el problema; donde el objeto, es la imagen, el elemento simbólico o representación; el sujeto es el docente universitario, y el problema sería cómo las representaciones son el reflejo de la realidad actual en un momento histórico y en un contexto determinado, en este caso la universidad.

Tendencias. Las representaciones sociales son un campo de expansión que se desarrolla al tenor del mundo en constante cambio, donde la diver- sidad, la heterogeneidad, la globalización, la internacionalización, la especialización del mundo, el particularismo retoman validez y requieren una mirada para encontrar puntos de convergencia y divergencia frente a una realidad que cada vez más debe ser mejor elaborada. En este orden de ideas, estas se convierten en un sistema de pre codificación de la realidad que direcciona actitudes, comportamientos, prácticas, creencias y posturas que permiten a los sujetos una justificación frente a su posición y al papel que desempeñan según el contexto en el que se movilizan.

A partir de los estudios epistemológicos, la nueva mirada de las representaciones permite abordar distintos paradigmas en la sociedad actual y futura como huella indeleble de una realidad en un momento histórico; es un espitemos emergente de una sociedad en constante evolución, es una nueva visión del holismo social en los medios universitarios, son una alternativa emergente frente al papel del docente universitario en su ser, hacer y quehacer.

\section{Conclusiones}

Las representaciones sociales contribuyen en la construcción de identidades que definen y caracterizan a los actores del proceso enseñanza-aprendizaje, donde el docente es el actor protagónico al dejar una huella indeleble en sus estudiantes y en la sociedad.

Las representaciones sociales deben ser consideradas como construcciones sociales, dinámicas y co-construidas; su análisis debe estar enfocado en una actitud de interrelación e intercambio de métodos. No son un modelo en abstracto de una teoría, sino una nueva forma de ver el mundo.

Las representaciones sociales aparecen como una red de ideas, metáforas e imágenes, móviles y dinámicas, considerando su carácter argumentativo y deliberativo; su estudio permite entender la dinámica de las interacciones sociales y aclarar los determinantes de las prácticas sociales pues la re- 
presentación, el discurso y la práctica generan elementos de juicio para identificar el rol del docente universitario.

Las representaciones sociales de los docentes universitarios constituyen una formación subjetiva, multifacética y de diversas formas, donde fenómenos de la cultura, la ideología y la pertenencia socio-estructural dejan su huella; de igual manera los elementos afectivos, cognitivos, simbólicos y valorativos.

El discurso y el rol docente son agentes de gran impacto en cualquier sociedad, las representaciones sociales se pueden estudiar a partir de ellos para comprender mejor las tendencias, para proponer caminos de nuevos escenarios frente a los aspectos positivos o negativos que se puedan detectar a partir de estas ya que son un concepto transversal en todas las disciplinas humanas y sociales.

La educación superior debe posibilitar el conocimiento de las representaciones sociales que circulan en el contexto educativo, analizar su incidencia en el comportamiento individual y grupal, permitiendo comprender el trabajo de los actores educativos, su impacto e intervención en los procesos encaminados hacia una mejor educación.

\section{Referencias}

Abric, J. (1994). Prácticas y representaciones sociales. Paris. PUF, 73p. (Versión digital).

Alves-Mazzotti, A. (2008). Representações Sociais: aspectos teóricos e aplicações à educação. Revista Múltiplas Leituras, 1(1), 18-43.

Ayala, J. (2009). Las representaciones sociales de la calidad de la pedagogía de dos instituciones de educación superior. México: UPN.

Balduzzi, M. (2011). La Psicología Social ante los Problemas y Desafíos de Las Sociedades Contemporáneas. Representaciones Sociales de Estudiantes
Universitarios y su Relación Con el Saber. Recuperado de: http://www.scielo.org.ar/scielo.php?scrip$\mathrm{t}=\mathrm{sci}$ _arttext\&pid=S1515-94852011000100006

Cardoso, J. (2011). Contenido y estructura de las representaciones sociales. Recuperado de: http:// revistas.udistrital.edu.co/ojs/index.php/infancias/ article/view/8366

Caparrós, A. (1984). La Psicología y Sus Perfiles. Barcelona: Barcanova.

Casado, E., \& Calonge, S. (Eds) (2000). Representaciones Sociales y Educación. Caracas: Cuadernos de Postgrado. 25, CEP-FHE. Universidad Central de Venezuela. Recuperado de http://www.scielo.org. ve/scielo.php?pid=s0798-97922002000100005\&script=sci_arttext

Casado, E., \& Martínez, C. (1998). La interacción Pedagógica como objeto de Representaciones Sociales. Boletín de Psicología, 61,31-45.

Castorina, J. (2012). Construcción Conceptual y Representaciones Sociales. El Conocimiento de la Sociedad. Recuperado de: http://www.pcyps.com/ wp-content/uploads/2012/10/Castorina-Barreiro-Toscano-Dos_versiones_del_sentido_comun 1 . pdf

Doise, W. (1993). Logique Sociales dans le raissonement. Paris: Delachaux et Niestlé.

Elgueta, V. (1998). Sobre la Representación de la Transición o sobre la transición de la Representación. Ensayo respecto de la interacción de las Representaciones sociales que acontecen en el aula. Recuperado de: http: www.nalejandría,com,or/ oo/colab/representaciónhtm

García, M. (2007). Representaciones Sociales. Teoría e Investigación. Recuperado de: https://books.google.com.co/ books?id=X3Eb7sKFaWMC\&pg=PA253\&lp$\mathrm{g}=\mathrm{PA} 253 \& \mathrm{dq}=$ las+representaciones+socia- 
les+\%28Garcia,+1993\%29.\&source=bl\&ots=KDP2Y9Y0J7\&sig=AA3q7pQzagQHoaUWL00769iDkl0\&hl=es\&sa $=X \& e i=v T R K V Z 6 U O Y a X N q r f g b g-$ D\&ved $=0 C E A Q 6 A E w B A \# v=$ onepage $\& q=l a s \% 20$ representaciones\%20sociales\%20(Garcia\%2C\%20 1993).\&f=false

Guilly, M. (1980). Mi/leo socio-famiPot' statut scoloire et représentation de l'éleve par le maitre a l'école primaire. Psychologie francaise, 21, 159-173.

Gilly, M. (1986). Las Representaciones Sociales en El Campo Educativo. Recuperado de: http://revistas.udistrital.edu.co/ojs/index.php/enunc/article/ view/1717/2330

Ibáñez, T. (1988). Ideologías de la vida cotidiana. Psicología de las representaciones sociales. Barcelona: Sendai.

Jodelet, D. (1986). La representación social: fenómenos, concepto y teoría. Psicología Social II. Pensamiento y vida social. Psicología social y problemas sociales. Barcelona: Ediciones Paidós.

Jodelet, D. (1989). La representación social: fenómenos, concepto y teoría. En Moscovici, S. Psicología Social, II. Pensamiento y Vida Social. Psicologia social y problems sociales. Barcelona-Buenos Aires-México: Paidós.

Jodelet, D. (1991). Représentation Sociale. En Grand Dictionnaire de la Psychologie. Paris: Larousse, 168 $-672$.

Jodelet, D. (2000). La vigencia de las representaciones sociales. Barcelona: Paidós.

Mireles, O. (2008). Investigación educativa en representaciones sociales: su producción en México de 1992 a 2005. En Arbesú I., Gutiérrez, S. \& Piña, J. M. (Coords.). Educación superior. Representaciones sociales. México: Gernika.
Mireles, O. (2011). Representaciones Sociales: Debates y Atributos para el estudio de la Educación. Revista Sinéctica, 36.

Moscovici, S. (1961). El psicoanálisis, su imagen y su público. Buenos Aires: Editorial Huemul S.A.

Moscovici, S. (1981). La era de las multitudes. Un tratado histórico de psicología de masas. México: Fondo de Cultura Económica.

Moscovici, S. (1988). Psicología Social. Buenos Aires: Huemul.

Moscovici, S., \& Jodelet, D. (1989). El psicoanálisis, su imagen y su público. Buenos Aires: Huemul.

Pereira, M. (1999). A propósito de las representaciones sociales: apuntes teóricos, trayectoria y actualidad". Informe de investigación. CIPS. La Habana. Recuperado de: http://www.psicologia-online. com/articulos/2007/representaciones_sociales. shtml

Pereira de Sá, C. (1998). A construção do objeto de pesquisa em representações sociais. Rio de Janeiro: Editora da Universidade do Estado do Rio de Janeiro, EdUERJ.

Perner, J. (1991). Understanding the representation mind. Cambridge: MA. The MIT Press. Versión española: Comprender la mente representacional. Barcelona: Paidós, 1994.

Shapere, D. (1979). Las teorías científicas y sus dominios en F. Suppe (Ed). La Estructura de las Teóricas Científicas. Madrid: Editora Nacional.

UNESCO, (2014). Situación actual de la educación en el mundo. Informe de gestión. Recuperado de: http://www.unesco.org/new/fileadmin/MULTIMEDIA/FIELD/Santiago/pdf/reporteanualfinal.pdf 